\title{
PERANCANGAN SISTIM E-COMMERCE UNTUK MEMPERLUAS PASAR HASIL OLAHAN SIDAT
}

\author{
Wiwin Windihastuty ${ }^{1}$, Titin Fatimah ${ }^{2}$, Samsinar ${ }^{3}$ \\ 1),2),3) Fakultas Teknologi Informasi, Universitas Budi Luhur \\ J1 Ciledug Raya, Petukangan Utara, Jakarta Selatan \\ wiwin.windihastuty@budiluhur.ac.id
}

\begin{abstract}
ABSTRAK
Kegiatan penjualan yang terbatas menyebabkan sejumlah industri tidak bisa berkembang dengan baik. Besar kecilnya mobilitas dan liberalisasi jual beli, membuat pihak manajemen harus melakukan inovasi perluasan pasar. Pemanfaatan E-Commerce menjadi tujuan penelitian untuk menghasilkan sistem yang dapat memberikan kemudahan dalam mengenalkan hasil olahan sidat di Indonesia secara global. Memperluas area pangsa pasar dan upaya untuk meningkatkan volume penjualan dengan cara membangun hubungan komunikasi yang bersifat interaktif dengan konsumen (pelanggan). Waterfall menjadi metode perancangan sistem E-Commerce dengan pendekatan berorientasi objek. Hasil perancangan sistem E-Commerce diharapkan dapat menampilkan semua informasi mengenai produk yang berupa hasil olahan sidat Indonesia. Sistem penjualan tidak lagi hanya fokus kepada masyarakat setempat saja, tetapi dapat melayani pasar luar asing. Sistem E-Commerce memberikan kemudahan bagi pengunjung, dalam hal ini e-Commerce dirancang memiliki kontribusi menyelesaikan persoalan untuk memberikan jaminan layanan informasi yang lebih dekat kepada konsumen (pelanggan), menampilkan pesan-pesan tertentu dalam mengarahkan pengunjung, calon pembeli dapat melakukan proses pemesanan, pembayaran dapat melalui transfer, cash on delivery dan PayPal, dan konfirmasi pembayaran produk melalui email. Kenyataan ini dapat memperluas pangsa pasar dan menumbuhkan daya saing secara global karena sistem penjualannya tidak lagi terbatas hanya pada wilayah tertentu saja.
\end{abstract}

Keyword : E-Commerce, Transfer, Cash on Delivery, Paypal, Waterfall .

\section{PENDAHULUAN}

\subsection{Latar Belakang}

Pemanfaatan teknologi informasi dalam bidang perniagaan telah berkembang dengan sangat pesat melalui sejumlah perubahan yang sangat signifikan dalam bentuk digitalisasi, mobilitas modal dan liberalisasi informasi (Laudon \& Traver, 2013). Konsumen (pelanggan) dapat melakukan pemesanan dan pembelian tanpa batasan tempat dan waktu, tanggap akan kekinian informasi (Xiaohui dkk., 2014). Ekspansi usaha menjadi lebih fleksibel, menjangkau pasar sasaran lebih luas, media promosi lebih murah dan interaktif, kejelasan transparansi biaya operasional, digitalisasi produk/jasa, memperlancar sistem pendistribusian, memberikan kemudahan transaksi komersial melintasi batasbatas budaya dan negara dengan biaya yang relatif lebih efektif, mempermudah membangun kemitraan bisnis dengan pola diferensiasi yang sesuai kebutuhan dengan spesifikasi produk/jasa tertentu (Li \& Hong, 2013).

Keberhasilan E-Commerce lebih dominan terletak kepada kekhususan produk dengan spesifikasi tertentu. Usaha bisnis dengan produk yang unik dan spesifik dapat menjadikan peluang bisnis dan memiliki tingkat komparatif yang tinggi karena memiliki ciri khas dan belum ada pada usaha bisnis yang lai seperti halnya usaha bisnis dalam budidaya sidat untuk menjual hasil olahan sidat. Pertumbuhan usaha bisnis budidaya tidak terlalu signifikan karena tidak dapat menjual didalam negeri, hal ini karena masyarakat lokal tidak banyak yang mengkonsumsi hasil olahan sidat. Kegiatan penjualan yang terbatas menyebabkan sejumlah pembudidaya sidat tidak bisa berkembang dengan baik karena jumlah pembelinya terbatas. Satu di antaranya adalah usaha PT Luhur Kasih Sakti, sejauh ini dengan kondisi penjualannya belum begitu baik dan cenderung stagnan membuat pemilik mencari terobosan baru dengan menjajaki peluang bisnis memperluas pangsa pasar secara online melalui pemanfaatan sistem E-Commerce.

Mobilitas dan liberalisasi pasar yang terbatas membuat pihak manajemen harus melakukan inovasi perluasan pasar sasaran melalui perancangan dan pemanfaatan E-Commerce. Teknologi ECommerce merupakan suatu mekanisme bisnis yang bekerja secara elektronik dengan memfokuskan kepada transaksi bisnis secara online dan memiliki kesempatan untuk membangun hubungan yang lebih manusiawi dan memiliki personalisasi dengan pelanggan tanpa bergantung kepada ruang dan waktu (Li \& Yang, 2014). Kenyataan ini dapat menumbuhkan daya saing secara global karena sistem penjualannya tidak lagi terbatas hanya pada wilayah tertentu saja. Selama ini sistem penjualannya masih mengandalkan media interaksi dengan konsumen (pelanggan) secara langsung dan masih berpusat pada lokasi tertentu khususnya di Indonesia. Hal ini tentunya menyulitkan pihak manajemen untuk meningkatkan jumlah penjualan 
dan memperluas area pemasarannya sampai di luar Indonesia.

\subsection{Tujuan Penelitian}

Tujuan penelitian ini adalah untuk menghasilkan sistem yang dapat memberikan kemudahan dalam mengenalkan dan menjual semua produk hasil olahan sidat secara global. Memperluas area pangsa pasar dan upaya untuk meningkatkan volume penjualan dengan cara membangun hubungan komunikasi yang bersifat interaktif dengan konsumen (pelanggan) melalui penyediaan alternatif antarmuka secara online sebagai media mempromosikan semua produk hasil olahan sidat PT Luhur Kasih Sakti.

\subsection{Kajian Pustaka}

E-Commerce merupakan bagian dari ebusiness. Di sisi penjual atau penyedia jasa ECommerce dapat melakukan pengumpulan informasi, misalnya data mengenai konsumen dimana seorang konsumen biasanya diminta untuk menjadi member terlebih dahulu sebelum melakukan transaksi lebih lanjut [1]. Pertama kali, tentunya seorang konsumen memerlukan informasi mengenai toko online mana yang menjual barang yang akan dibelinya dengan memanfaatkan teknologi search engine yang ada [2].

Beberapa situs E-Commerce menyediakan layanan bagi konsumen untuk bernegosiasi harga dengan penjual, namun beberapa situs ada pula yang menerapkan harga fixed yang tidak dapat dinegosiasikan [3]. Dalam suatu online catalog, atau web catalog, biasanya terdapat kategori dari barang yang ditawarkan, catalog barang-barang itu sendiri berikut daftar harga atau promosi lainnya, dan shopping cart atau istilahnya kereta belanja secara online [5].

Teknologi dibalik online catalog sebenarnya adalah situs atau portal E-Commerce itu sendiri yang didukung infrastruktur web atau internet [6]. Sistem E-Commerce berkenaan dengan transaksi digital untuk berbagai organisasi dan perorangan (individual), dapat menjangkau konsumen dan masyarakat lebih luas sehingga memiliki peluang untuk meningkatkan pertumbuhan pasar sasarannya [2]. Model transaksi ini memungkinkan transaksi komersial melewati batas negara dan budaya dengan jauh lebih nyaman dan dengan biaya yang lebih efektif daripada dalam kerangka perdagangan yang bersifat tradisional. Mekanisme teknologi tersebut dapat dioperasikan di mana saja untuk semua negara di dunia ini karena memiliki standar yang bersifat universal[9].

Semua pelaku bisnis mudah menjalin hubungan suatu bisnis dengan bisnis lainnya, dan memiliki hubungan langsung dengan konsumen [4]. Sistem E-Commerce sebagai suatu bentuk kemajuan teknologi informasi telah membawa sejumlah perubahan, di antaranya menurunkan biaya interaksi antara pembeli dan penjual, interaksi menjadi lebih mudah tanpa batasan waktu dan tempat, lebih banyak alternatif dan mempermudah promosi, peluang memperluas pangsa pasar tanpa harus memiliki modal dan investasi yang besar, transparansi bisnis dan kemudahan memberikan pelayanan kepada konsumen atau pelanggan [10].

E-Commerce di Indonesia yang relevan dengan penelitian ini di antaranya adalah "Pemanfaatan Teknologi Ecommerce Merupakan Sarana Penting dalam Menerapkan Strategi dan Promosi secara Online Sehingga dapat Memperluas Pangsa Pasar" [11]. Banyak sekali kemudahan dalam proses transaksi dan kekinian informasi sangat mendukung dalam proses pembuatan keputusan manajerial [12]. Penyebaran informasi menjadi lebih cepat dan adaptif terhadap berbagai perubahan kebutuhan masyarakat tanpa batasan waktu dan tempat[13]. Penurunan biaya operasional dan pencapaian profitabilitas perusahaan serta peluang meningkatkan daya saing perusahaan [14]. Sistem penjualan dan pemasaran menjadi lebih efektif, dinamis dan mudah dalam meningkatkan perluasan produk [16].

Penelitian ini menggunakan metode System Development Life Cycle (SDLC) dengan pendekatan Waterfall sehingga pendekatan yang digunakan tidak sama dengan penelitian sebelumnya. Metode ini memiliki fase-fase perencanaan kebutuhan, perancangan, unit testing, sistem testing dan pemeliharaan [20].

\section{METODE PENELITIAN}

Perancangan aplikasinya menggunakan pendekatan Waterfall (Shelly \& Rosenblatt, 2012). Pendekatan ini merupakan model klasik dan bersifat sistematis sehingga mudah memahaminya karena semua prosesnya bekerja secara berurutan dalam tahapan membangun sebuah perangkat lunak (Gambar 1).

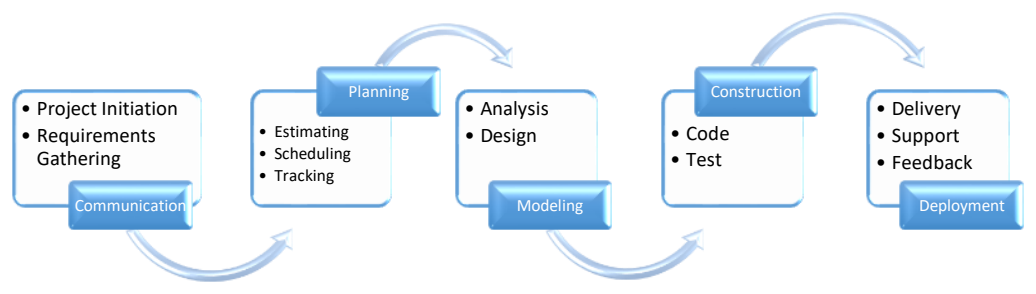

Gambar 1. Metode Waterfall 
Pendekatan Waterfall (Air Terjun). Metode ini berawal dari kegiatan perencanaan, pengembangan dan dievaluasi secara terus menerus untuk menetapkan apakah sistem informasi tersebut masih layak diaplikasikan, jika tidak, sistem informasi tersebut akan diganti dengan yang baru dan dimulai dari perencanaan kembali. Perencanaan sistem dimulai setelah adanya usulan baik dari internal maupun eksternal, dilanjutkan dengan keputusan manajemen. Setelah mendapatkan persetujuan manajemen, rencana tersebut akan disusun dalam suatu kerangka acuan kerja yang bersifat menyeluruh dan mencakup keseluruhan sistem. Tahap pengembangan sistem dilakukan melalui kegiatan survei, analisis, perancangan, pembangunan, implementasi dan pemeliharaan. Survei bertujuan untuk mengetahui ruang lingkup pekerjaan. Analisis bertujuan untuk memahami system yang ada, mengidentifikasi masalah dan mencari solusinya. Perancangan bertujuan mendesain sebuah sistem baru untuk menyelesaikan masalah-masalah yang dihadapi perusahaan. Pembangunan bertujuan menghasilkan sebuah sistem baru melalui sistem pengkodean komputerisasi. Implementasi bertujuan agar sistem yang dihasilkan dapat memberikan manfaat mengatasi persoalan yang terjadi dalam perusahaan. Untuk penerapannya menggunakan cara secara berurutan (waterfall), dimana setiap tahapan harus diselesaikan terlebih dahulu sebelum meneruskan ke tahapan berikutnya, dengan tujuan menghindari terjadinya pengulangan tahapan tersebut. Pemeliharaan bertujuan agar sistem dapat berjalan atau dioperasionalkan secara optimal. Tahap evaluasi dilakukan untuk memastikan bahwa pelaksanaan pengembangan system sesuai dengan rencana yang telah ditetapkan baik dari segi waktu, biaya maupun secara teknis.

Tim evaluasi meliputi user/manajemen dimulai saat pengembangan sistem, saat penyerahan dan saat pengoperasian. Selanjutnya untuk proses pembuatan perancangan prototipe sistem E-Commerce menggunakan basis komponen dengan menerapkan kerangka kerja CSS (Cascading Style Sheet), PHP (Personal Home Page), javascript framework, jQuery, CI (CodeIgniter), dengan memberdayakan MVC (Model View Controller). Untuk sistem pengujiannya menggunakan data yang mudah diperiksa (easy values), data yang sederhana dan mudah dihitung (typical realistic values), data yang ekstrim (extreme values) dan data yang tidak diperbolehkan (illegal values). Struktur pengujian ini penting mengingat perekaman data harus akurat dan tepat. Validasi proses input akan menentukan kualifikasi output dari sistem secara keseluruhan sehingga memudahkan dalam pembuatan keputusan manajerial. Kebutuhan analisis kesempatan perluasan pangsa pasar diawali dengan mengidentifikasi sejumlah pesaing sejenis, yang mana dalam usaha ini belum banyak yang memanfaatkan media internet dalam model penjualan online sehingga merupakan peluang yang bagus. Keterbatasan faktor teknis seperti kecepatan akses, kemampuan server dan kemudahan akses. Memberi kemudahan akses informasi yang selama ini masih menjadi persoalan. Media promosi yang dinamis dapat meningkatkan jumlah transaksi dan pelanggan. Belum semuanya memiliki jaringan infrastruktur internet yang stabil dan normal. Sisi produk memiliki faktor kekhasan khusus sehingga membutuhkan media digitalisasi produk dalam pasar virtual. Dalam merancang antarmuka menggunakan pendekatan 7C (Context, Content, Community, Customization, Communication, Connection, Commerce). Untuk komunikasi pasar dapat melalui mesin pencari, iklan online, media cetak dan majalah [20].

\section{PEMBAHASAN}

Kebutuhan perancangan proses bisnis sistem E-Commerce diawali dengan melakukan penelusuran, mengidentifikasi dan menganalisis untuk memenuhi semua kebutuhan informasi yang berhubungan dengan konten dan fitur-fitur yang melekat pada dimensi produk hasil olahan sidat. Kegiatan ini untuk menggali semua kebutuhan mengenai informasi setiap proses bisnis, agar model aplikasi dan prosedur situs perniagaan memiliki kesesuaian dengan proses bisnis konvensional. Hal ini dapat menawarkan peluang baru sekaligus menjadi solusi dari sejumlah batasan pada perusahaan dengan mempertimbangkan prosedur dan standardisasi operasionalnya.

Sistem digitalisasi perniagaan, mempertemukan pembeli dan pemasok/penjual secara online melalui tatanan situs E-Commerce tanpa lagi harus bergantung kepada lokasi serta waktu dalam melakukan proses transaksi bisnis. Cakupan analisis proses bisnis dari proses permintaan akan kebutuhan informasi sampai kepada proses validasi penerimaan oleh konsumen (pelanggan). Untuk kebutuhan spesifikasi sistem ECommerce dibedakan menjadi dua bagian penting, yaitu fungsional dan nonfungsional. Kebutuhan fungsional merupakan sisi kebutuhan yang berisi proses-proses untuk menjalankan system ECommerce. Selanjutnya kebutuhan nonfungsional lebih menitikberatkan kepada semua unsur properti perilaku sistem. Interaksi dan kemampuan mengelola stimulus semua elemen sistem dapat menjadi dukungan paling penting bagi keberhasilan menjalin hubungan dengan pelanggan dan calon pelanggan.

Perancangan arsitektur sistem E-Commerce memiliki dua bagian utama, yaitu halaman front-end dan back-end. Setiap bagian memiliki fitur dan kontennya masing-masing. Front-end adalah halaman yang menampilkan bagian depan situs Ecommerce yang berfungsi melayani pengguna dengan fitur-fitur yang sudah diatur sedemikian rupa 
agar memudahkan proses pembelanjaan pengetahuan dan pencarian informasi produk secara cepat dan tepat. Front-end merupakan halaman pengguna melakukan proses pembelanjaan online, mencari informasi harga dan produk serta berinteraksi dengan perusahaan. Sementara Backend merupakan halaman yang ditampilkan bagi admin dan pengaturan isi data didalam situs frontend tersebut. Admin dapat menambah, mengedit, menghapus data yang ada, seperti data produk, data administrasi, data pesanan dan pada halaman backend admin juga bisa mengakses informasi lainnya yang bermanfaat. Halaman admin tidak dapat diakses langsung melalui menu pada index.php, melainkan harus dengan mengetikkan alamat tertentu pada browser sehingga tingkat keamanannya lebih tinggi.

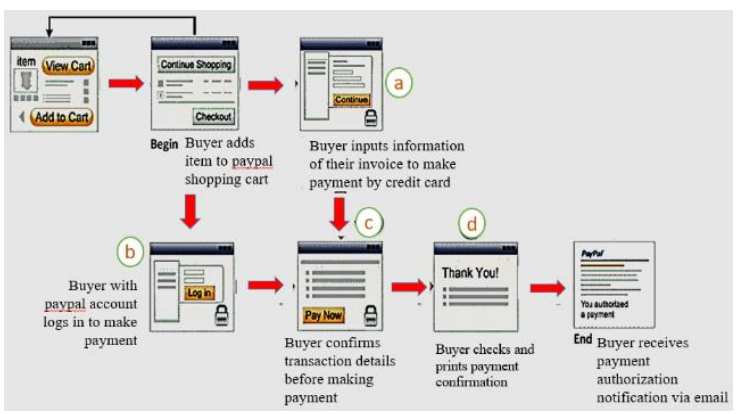

\section{Gambar 2. Sistem Arsitektur e-Commerce}

satu prinsip dalam merancang situs adalah memastikan bahwa setiap halaman memiliki sistem navigasi yang baik dan link yang mampu mengantar pengunjung ke halaman utama. Situs E-Commerce memiliki menu dibagian header, dimana untuk menu Katalog akan selalu update sesuai dengan link yang dikunjungi, menu akun Saya, menu Troli, menu Checkout. Selain menggunakan menu dibagian header, situs ini juga menggunakan link navigasi alternatif lainnya di bagian kiri dan kanan seperti Kategori, Produk Baru, Search, Shopping Cart, Bestseller, Viewed Product, Bookmark. Pada bagian footer terdapat trademark dari situs dan perusahaan. Sistem E-Commerce menggunakan arsitektur teknologi client server secara terpusat, karena dapat mengatasi masalah duplikasi gangguan. Hal ini dimaksudkan agar jika seorang pelanggan mengalami gangguan dalam mengakses data dari server maka gangguan tersebut tidak mempengaruhi pelanggan lain dalam melakukan pengaksesan data. Selain itu, tidak memerlukan biaya dalam jumlah yang besar karena server hanya berfungsi untuk menyimpan seluruh data pelanggan, data transaksi, dan informasi produk sehingga seluruh data yang ada dapat digunakan oleh client sesuai dengan fungsi dan tujuannya. Server menyediakan data sesuai dengan kebutuhan client sehingga dapat langsung beroperasi melalui jaringan yang tersedia. Keterhubungan ini memberikan suatu jejaring yang efektif untuk menjamin dan memastikan kelancaran perolehan informasi sehingga semua data transaksi dan umpan balik dari pelanggan dapat melakukan proses secara lebih efektif dan efisien.

Arsitektur E-commerce memiliki mekanisme pengelolaan proses bisnis dimulai dari pelanggan mengakses situs, kemudian pelanggan membeli barang dengan cara menambahkan item barang ke dalam keranjang belanja. Setelah belanja selesai, maka pembeli dapat memasukkan informasi penagihan ke dalam kartu kredit atau pembeli yang sudah memiliki account PayPal dapat melakukan login guna melakukan pembayaran. Sebelum melakukan pembayaran, pembeli melakukan konfirmasi rincian dari transaksi, berikutnya pembeli melihat dan mencetak konfirmasi pembayaran. Langkah terakhir adalah pembeli menerima pemberitahuan pembayaran dari email. Arsitektur metode pembayaran dengan PayPal dimulai dari pelanggan belanja dengan memasukkan item barang ke dalam keranjang belanja. Setelah belanja, langkah selanjutnya pelanggan harus login. Setelah berhasil login, pelanggan dapat melihat data pengiriman dan informasi tagihan kemudian melakukan pembayaran. Setelah melakukan pembayaran, pelanggan dapat melihat pesanan secara detail dan kemudian pelanggan melihat konfirmasi dari barang pesanan.

Arsitektur cara kerja pembayaran faktur secara online dimulai dari pengiriman faktur. Selanjutnya pelanggan mengeklik link pembayaran yang ada didalam faktur untuk melakukan pembayaran. Setelah proses pembayaran dilakukan, maka dana nasabah dipindahkan dari bank nasabah ke bank dengan jaringan pembayaran. Setelah semua kegiatan pembayaran selesai, maka langkah terakhir adalah pelanggan mencocokkan dengan faktur asli

\section{KESIMPULAN}

Perancangan sistem E-Commerce khusus produk hasil olahan sidata memiliki fasilitas untuk menyimpan data pribadi member (anggota) dengan dilengkapi dengan username dan password untuk mengantisipasi penyalahgunaan oleh orang-orang yang tidak bertanggung-jawab. Sistem E-Commerce ini juga menyediakan fasilitas pembayaran melalui transfer bank dan Cash On Delivery. Selain itu, aplikasi ini menyediakan fitur menarik untuk member seperti program ajak teman, dan pemberian hadiah berupa voucher diskon belanja saat member ulang tahun. Arsitektur aplikasi ini juga dapat digunakan untuk memasukkan data baru dan mengubah data yang sudah ada serta dapat memberikan informasi data pembelian yang dilakukan member kepada pemilik toko. Memberikan informasi kepada member mengenai status pengiriman barang yang dibelinya dan status pembayarannya melalui e-mail. Agar implementasi e-commerce berjalan baik, terutama disisi client maka diperlukan hosting server yang memiliki kapasitas besar dan kecepatan akses yang cepat. 
Untuk pengembangan lebih lanjut, Situs sistem E-Commerce ini dapat menambahkan fasilitas berita mengenai perkembangan informasi dan teknologi agar pengguna dan pengunjung dapat mengikuti perkembangan terkini. Melengkapi dengan sistem pembayaran secara elektronik menggunakan kartu kredit atau sistem pembayaran elektronik lainnya seperti PayPal. Menyediakan beberapa opsi bahasa untuk memberikan kemudahan kepada pelanggan yang memiliki kewarganegaraan asing, dan berdomisili di Indonesia untuk melakukan pemesanan atau transaksi.

\section{DAFTAR PUSTAKA}

[1]. Laudon, K. C., \& Traver, C. G. (2013). ECommerce 2014: Business, Technology, Society. Tenth Edition. Prentice-Hall, Inc.

[2]. Xiaohui, G., Rong, G., \& JianYu, W. Chongning, Huo. (2014). Key Technology of Distributed E-Commerce System Architecture. TELKOMNIKA Indonesian Journal of Electrical Engineering. Vol.12. No.5. May 2014. Page. 3987- 3993. DOI:

[3]. Li, H., \& Hong, J. (2013). Factors Influencing Consumers' Online Repurchasing Behavior: A Review and Research Agenda. iBusiness. 5(4). Page.161166.

[4]. Li, Y., \& Yang, R. (2014). New Business Model for Company to Win the Competition. American Journal of Industrial and Business Management. Vol 4. Page. 190-198.

[5]. Lee, In. (2014). Trend in E-Business, EServices, E-Commerce: Impact of Technology on Goods, Services, and Business Transactions. IGI Global.

[6]. Li, Lixiang., Chai, Yueting., \& Liu, Yi. (2011). Inter-Group and Intra-Group Externalities of Two-Sided Markets in Electronic Commerce. Journal of Service Science and Management. Scientific Research, Vol 4, Page. 52-58.

[7]. Schneider, G. (2012). Electronic Commerce. Tenth Edition. Cengage Learning.

[8]. Shelly, G., \& Rosenblatt, H. (2012). System Analysis and Design. Ninth Edition. Course Technology. Cengage Learning.

[9]. Kwahk, K. Y., \& Ge, X. (2012). The Effects of Social Media on E-Commerce: A Perspective of Social Impact Theory. 45th Hawaii International Conference on System Sciences. ISBN: 978-0-7695-4525-7/12 (C) 2012 IEEE DOI 10.1109/ HICSS.2012.564. Page. 1814-1823.

[10]. Kwahk, K. Y., \& Ge, X. (2012). The Effects of Social Media on E-Commerce: A Perspective of Social Impact Theory. 45th
Hawaii International Conference on System Sciences. ISBN: 978-0-7695-4525-7/12 (C) 2012 IEEE DOI 10.1109/ HICSS.2012.564. Page. 1814-1823.

[11]. Bernadi, J. (2013). Aplikasi Sistem Informasi Penjualan Berbasis Web Pada Toko Velg YQ. ComTech. 4(2). Page. 731-741.

[12]. Antika, E., \& Widiastuti, I. (2014). Pengembangan E-Commerce dan Strategi Promosi Online Batik Tulis Sumbersari untuk Memperluas Jaringan Pemasaran Melalui Internet. Konferensi Nasional Sistem dan Informatika (KNS\&I) 2014. ISSN: 19799845. STMIK STIKOM Bali. 7-8 November 2014., Page. 278-283.

[13]. Anwar, S., \& Efendi, Y. (2014). Desain dan Implementasi E-Commerce Untuk UKM Berbasis Komunitas: Studi Kasus UKM Di Wilayah Pamulang. Konferensi Nasional Sistem Informasi (KNSI) 2014. ISSN: 23551944. STMIK Dipanegara Makassar Bekerja sama Dengan ITB. 27 Pebruari - 01 Maret 2014. Page. 1569-1573.

[14]. Astuti, R., \& W, Pariyadi. (2013). Aplikasi E-Commerce Pada Systech Computer Jambi. Seminar Nasional Informatika (SNIf) 2013. STMIK Potensi Utama Medan. Page. 348352.

[15]. Julisar., \& Miranda, E. (2013). Pemakaian ECommerce Untuk Usaha Kecil dan Menengah Guna Meningkatkan Daya Saing. ComTech. Vol. 4. No. 2. Desember 2013. Page. 638-645.

[16]. Kosasi, S. (2014). Pembuatan Sistem Informasi Penjualan Berbasis Web Untuk Memperluas Pangsa Pasar. Seminar Nasional Teknologi dan Informatika (SNATIF) 2014. ISBN: 978-602-1180-04-4. Edisi 1. Volume 1. Universitas Muria Kudus. 23 Agustus 2014. Page. 225-232.

[17]. Kosasi, S. (2015). Perancangan dan Pemanfaatan E-Commerce Untuk Memperluas Pasar Produk Furniture. Seminar Nasional Teknologi Informasi dan Komunikasi (SENTIKA) 2015. Universitas Atma Jaya Yogyakarta. ISSN: 2089-9815. Page. 17-24.

[18]. Sommerville, I. (2011). Software Engineering, Ninth Edition. AddisonWesley.

[19]. Turban, E., King, D., \& Lang, J. (2010). Introduction to Electronic Commerce. Third Edition. Prentice-Hall, Inc.

[20]. Mohapatra, S. (2013). E-Commerce Strategy: Text and Cases (Springer Texts in Business and Economics). New York: Springer. 